\title{
POLÍTICAS LINGUÍSTICAS PARA LÍNGUAS ADICIONAIS NA BNCC: CONTRIBUIÇÕES PARA A FORMAÇÃO DE PROFESSORES
}

\author{
Políticas lingüísticas para lenguas adicionales en la BNCC: Contribuciones \\ para la formación de profesores
}

Marcela Dezotti CÂNDIDO Universidade Federal de Minas Gerais marcela.linguistica@gmail.com https://orcid.org/0000-0002-4994-8324

Camila de Souza SANTOS Universidade Federal de Minas Gerais camila.pla14@gmail.com https://orcid.org/0000-0002-2706-6304

Silvana Maria MAMANI

Universidade Federal de Goiás silvanamariamamani@gmail.com https://orcid.org/0000-0003-1249-7889

\begin{abstract}
RESUMO: Neste artigo tratamos de uma questão específica referente a políticas linguísticas na Base Nacional Comum Curricular (BNCC): como as línguas adicionais e as competências tecnológicas são vistas neste importante documento, que orienta práticas docentes em escolas de todo o Brasil. Justificamos estabelecer relação entre esses dois focos, uma vez que o contexto de ensino-aprendizagem de línguas adicionais costuma ser fortemente marcado pela presença das tecnologias digitais. Com base em uma metodologia documental e interpretativista e em teóricos da área de política linguística (SPOLSKY, 2004; SCHIFFMAN, 1996; SHOHAMY, 2006; RAJAGOPALAN, 2013a, 2013b; ROJO, 2013; DINIZ; RIBEIRO DA SILVA, 2019), nossa análise aborda as orientações elaboradas para as séries finais do ensino fundamental $\left(8^{\circ} \mathrm{e}\right.$ $9^{\circ}$ anos), suas contribuições e possíveis impactos para a prática docente. Os resultados apontam que as orientações da BNCC carecem de algumas explicações teóricas acerca de conceitos que envolvem a área de língua adicional, além de direcionamentos curriculares para línguas adicionais diferentes ao inglês, o que demanda uma formação docente sólida para preencher as lacunas encontradas.
\end{abstract}

PALAVRAS-CHAVE: Políticas Linguísticas; Línguas Adicionais; Base Nacional Comum Curricular. 
RESUMEN: En este artículo tratamos de un tema específico acerca de políticas lingüísticas en la Base Nacional Común Curricular (BNCC) (BRASIL, 2017a): como las lenguas adicionales y las competencias tecnológicas son abordadas en ese importante documento, que guía las prácticas de enseñanza en escuelas de todo el Brasil. Justificamos establecer una relación entre esos dos enfoques, ya que el contexto de enseñanza-aprendizaje de lenguas adicionales suele estar fuertemente marcado por la presencia de las tecnologías digitales. Con base en una metodología documental e interpretativista y de teóricos del área de políticas lingüísticas (SPOLSKY, 2004; SCHIFFMAN, 1996; SHOHAMY, 2006; RAJAGOPALAN, 2013a, 2013b; ROJO, 2013; DINIZ; RIBEIRO DA SILVA, 2019), nuestro análisis aborda las orientaciones elaboradas para los últimos años de enseñanza básica $\left(8^{\circ} \mathrm{e}\right.$ $9^{\circ}$ años), sus contribuciones y posibles impactos para la práctica docente. Los resultados apuntan que en las orientaciones de la BNCC carecen algunas explicaciones teóricas acerca de los conceptos que rigen al área de lengua adicional, además de direccionamientos curriculares para lenguas adicionales diferentes al inglés, lo que demanda una formación docente sólida para contribuir con esos lapsos encontrados.

PALABRAS CLAVE: Políticas Lingüísticas; Lenguas Adicionales; Base Nacional Común Curricular.

\section{INTRODUÇÃO}

O presente trabalho faz parte de uma pesquisa autônoma das autoras, que vêm se dedicando, nos últimos anos, aos estudos de políticas linguísticas e formação de professores de línguas adicionais, conceitos que também sustentam suas práticas e reflexões pedagógicas enquanto docentes da Educação Básica e do Ensino Superior.

Nosso objetivo é investigar como são vistas as línguas adicionais na Base Nacional Comum Curricular (doravante BNCC), assim como as competências tecnológicas para as séries finais do ensino fundamental ( $8^{\circ}$ e $9^{\circ}$ ano). Justificamos a relação entre línguas adicionais e tecnologias digitais por considerarmos fundamental que as políticas linguísticas que conduzem o ensino de línguas proporcionem orientações para práticas que envolvem o uso de recursos digitais aos aprendizes para se apropriarem de recursos que lhes possibilitem maior autonomia, motivação e engajamento no desenvolvimento de suas competências linguísticas. Assim sendo, acreditamos que as tecnologias digitais possam motivar esse engajamento comunicando as práticas de sala de aula ao cotidiano cada vez mais conectado dos aprendizes, especialmente, nas séries focalizadas neste trabalho.

Enquanto professoras do Ensino Básico e de cursos de graduação em Letras, 
identificamos as dificuldades dos docentes e dos alunos em formação em compreender e aplicar, na prática escolar, as orientações da BNCC, o que justifica o aprofundamento teórico e reflexivo realizado no presente estudo. As perguntas que motivaram a presente pesquisa são operacionalizadas em torno de duas questões: 1) Como a BNCC orienta o trabalho com as diferentes habilidades comunicativas em língua adicional ${ }^{1}$ e de que forma essas orientações impactam o fazer do professor? 2) Como a BNCC orienta o uso das tecnologias digitais para o desenvolvimento das diferentes habilidades comunicativas em línguas adicionais?

No que se refere às diretrizes nacionais para a educação no Brasil nas últimas décadas, a Constituição Federal já previa a elaboração dos currículos elementares para os estudantes do ensino fundamental, uma vez que "serão fixados conteúdos mínimos para o ensino fundamental, de maneira a assegurar formação básica comum e respeito aos valores culturais e artísticos, nacionais e regionais" (BRASIL, 1988, Art. 210). De forma similar, na Lei $n^{0} 9.394$ de Diretrizes e Bases da Educação Nacional (LDB) (BRASIL, 1996) ratifica-se a importância da existência desses currículos mínimos para o ensino fundamental e médio, pois "devem ter uma base nacional comum, a ser complementada, em cada sistema de ensino e estabelecimento escolar, por uma parte diversificada, exigida pelas características regionais e locais da sociedade, da cultura, da economia e da clientela" (BRASIL, 1996, Art. 26). No mesmo artigo, no inciso 5, especifica-se as diretrizes para ensino de língua adicional nas quais "será incluído, obrigatoriamente, a partir da quinta série ${ }^{2}$, o ensino de, pelo menos, uma língua estrangeira moderna" (BRASIL, 1996, Art. 26) e a escolha desse idioma ficaria a cargo das instituições, de acordo com a comunidade escolar. Em consonância com essa legislação, em 1997 foram elaborados os Parâmetros Curriculares Nacionais (PCNs) (BRASIL, 1997) para as primeiras séries da educação fundamental, cujo objetivo era direcionar o trabalho do

\footnotetext{
${ }^{1}$ Tendo por base Leroy (2018), Jordão (2014) e Schlatter e Garcez (2009), adicional é a língua considerada não materna pelo aluno na condição de língua que "acrescenta" valores e que, inclusive, pode comunicar-se com a língua-cultura do aprendiz, formando com esta uma ponte intercultural que se dá por meio do diálogo entre o que o aluno já sabe de sua língua-cultura e o que ele tem a ampliar a partir da aprendizagem de outro idioma. Nessa concepção, o termo "estrangeiro" poderia se referir a uma noção de língua distante do estudante, de língua do outro, de uma cultura que está fisicamente e socialmente distante desse aprendiz, não sendo enfatizada a possibilidade de diálogo intercultural. Outra questão que sustenta a concepção de língua adicional é o fato de "adicional" tratar-se de um termo amplo na condição de um idioma não materno, podendo este ser idioma de acolhimento, de herança, segunda, terceira, quarta língua não materna aprendida pelo sujeito em contexto ou não de imersão.

${ }^{2}$ Essa série, atualmente, corresponde à $6^{\circ}$ na designação de níveis de aprendizagem na Educação Básica.
} 
professor em sala de aula. Posteriormente, foram publicados os Parâmetros Curriculares Nacionais para os anos finais do ensino fundamental, isto é, da $5^{\mathrm{a}}$ a $8^{\mathrm{a}}$ séries (BRASIL, 1998) e as Diretrizes Curriculares Nacionais da Educação Básica (BRASIL, 2013), documento que passa a considerar nove anos de ensino fundamental.

No âmbito nacional, em 2014 é publicado o Plano Nacional de Educação (PNE) para todos os níveis do sistema educacional, decorrente da aprovação da Lei número 13.005 de 2014. A vigência do PNE é de dez anos (BRASIL, 2014) e, dentre as particularidades, o documento prevê metas que deveriam ser cumpridas nos currículos de acordo com o prazo estabelecido. Posteriormente, entre 2014 e 2017, aconteceu o processo de elaboração da BNCC (BRASIL, 2017a), que culminou em 20 de dezembro de 2017, com a publicação da Resolução $\mathrm{CNE} / \mathrm{CP} \mathrm{n}^{0} 2$, que institui e orienta a implantação da BNCC em todo o território nacional.

Apresentado o panorama geral que descreve a instauração de documentos que direcionam a Educação Básica no Brasil, reiteramos nosso foco de análise sobre a BNCC, e, a seguir, apresentamos os procedimentos teóricos e metodológicos que fundamentam a pesquisa.

\section{POLÍTICAS LINGUÍSTICAS NO CONTEXTO DE LÍNGUAS ADICIONAIS}

Com base nas concepções apresentadas anteriormente, orientamos esse estudo, por meio de uma metodologia documental, a fim de interpretar e sintetizar as informações a que tivemos acesso no documento oficial analisado, com o propósito de fazer inferências e produzir interpretação coerente com base em nossos objetivos de pesquisa (SÁ-SILVA; ALMEIDA; GUINDANI, 2009). Ademais, nos apoiamos na pesquisa de base interpretativista de Moita Lopes (1994), perspectiva que considera tanto o pesquisador quanto os fatos sociais como indissociáveis, de modo que os responsáveis pela investigação sejam integrantes do processo de conhecimento e possam interpretar fenômenos analisados, atribuindo-lhe um significado. Essa metodologia considera a linguagem como a "determinante central do fato social" e "o meio de se ter acesso a sua compreensão através da consideração de várias subjetividades/interpretações dos participantes do contexto social sob investigação e de outros pesquisadores" (SÁ-SILVA; ALMEIDA; GUINDANI, 2009, p. 333). 
Com relação aos conceitos debatidos por teóricos da área de políticas linguísticas, iniciamos nossa discussão com Rajagopalan (2013a), autor que salienta que o campo da política linguística vai além da militância linguística e "é a arte de conduzir as reflexões em torno de línguas específicas, com o intuito de conduzir ações concretas de interesse público relativo à(s) língua(s) que importam para o povo de uma nação, de um estado ou ainda, instâncias transnacionais maiores" (ibidem, p. 21). Nessa direção, Diniz e Ribeiro da Silva (2019) discutem algumas divergências epistemológicas nas pesquisas sobre política linguística em que mostram duas linhas de divergência com foco: a) nas políticas linguísticas oficiais versus as de facto e b) nos atores versus os sujeitos de políticas linguísticas. Embora entendamos a importância de ambas as linhas, de acordo com nossos objetivos de pesquisa, aprofundamos nossa discussão considerando apenas o primeiro item.

Desde a sua origem em meados do século XX, a área de política linguística era conhecida por meio do termo "planejamento da linguagem" ou "planejamento linguístico", e, de acordo com Diniz e Ribeiro da Silva (2019), esse conceito foi adotado por pesquisadores da área da Sociolinguística, cujas pesquisas visavam à solução de problemas em diferentes partes do mundo. Para os autores (ibidem), no entanto, a adição do termo "política" à nomenclatura da área é recente. No que diz respeito ao termo "política e planejamento da linguagem", foi amplamente utilizado na literatura em inglês sob uma perspectiva que distingue política linguística (ou fato de tomar decisões) em uma determinada situação sociolinguística do seu par, o planejamento linguístico (a implementação). Nessa perspectiva, Calvet (2002, p. 145, tradução nossa), afirma que a política linguística diz respeito a "um conjunto de escolhas conscientes referentes às relações entre língua(s) e vida social" ou "determinação das grandes decisões referentes às relações entre as línguas e as sociedades" (CALVET, 2007, p. 11), enquanto o planejamento linguístico consiste na "implementação prática de uma política linguística, em suma, a passagem ao ato". Ainda nessa perspectiva, o Estado é o principal agente e responsável pela sua implementação para promover determinada(s) língua(s), modificar o status e/ou sua função social (CALVET, 2002). Essa visão preocupa-se com as decisões dos órgãos oficiais, e, de acordo com Diniz e Ribeiro da Silva (2019), dentre as implicações dessas políticas linguísticas encontra-se a promoção de uma determinada língua em detrimento de outras. 
Retomados por Diniz e Ribeiro da Silva (2019), autores como Spolsky (2004), Schiffman (1996) e Shohamy (2006) têm visões ampliadas do conceito de política linguística, uma vez que entendem esse termo explicitado em documentos oficiais não necessariamente coincidindo com a que ocorre nas práticas sociais. Nesse sentido, Diniz e Ribeiro da Silva (2019) se referem ao trabalho de Schiffman (1996), que considera a política linguística relacionada às características culturais de uma sociedade. Nessa comunidade, as crenças em relação à sua língua materna poderiam, por exemplo, determinar certas atitudes para outros idiomas. Essas crenças também poderiam influenciar determinações, como a manutenção e a transmissão de línguas e a promoção (ou não) do ensino-aprendizagem de determinadas línguas adicionais. Já as contribuições de Spolsky (ibidem) marcaram um ponto de inflexão na concepção tradicional do conceito e seu trabalho considera o funcionamento das políticas linguísticas (não) oficiais e a existência dessas políticas mesmo quando não explicitadas ou estabelecidas pelos agentes oficiais do Estado. Complementando o modelo proposto por Spolsky (2004), Shohamy (2006) faz uma distinção entre a política linguística de jure e de facto, que, por meio de uma série de mecanismos, poderiam contribuir para a perpetuação e reprodução de ideologias numa sociedade. Nessa direção, a autora (2006) enfatiza as políticas linguísticas de facto e suas agendas ocultas, ou seja, em que medida podem ser explícitas (ou não). A política linguística oficial brasileira, expressa nos textos legislativos (como, por exemplo, a BNCC), seria um exemplo explícito, enquanto materiais didáticos, exames de proficiência etc., seriam considerados mecanismos implícitos.

Por sua vez, Rojo (2013) cita três maneiras de se fazer política linguística que implique em mudanças sociais efetivas para o nosso país: (1) prestação de serviços de assessoria e organização de extensões a entidades da sociedade civil ou a órgãos estatais; (2) atuação nas políticas públicas em órgãos estatais, assim como ministérios (de Educação, de Cultura) e secretarias (de Estado, de Município), entre outros; (3) planejamento e execução de políticas públicas, de modo a pesquisar seus efeitos e resultados para corrigir rumos de ação política - maneira mais recente de participação política, mas ainda rara nos estudos da Linguística Aplicada (LA).

Como um de nossos objetivos de pesquisa é analisar como as línguas adicionais e as competências tecnológicas são vistas, pautamo-nos em Rajagopalan (2013b), autor que salienta a importância de propor orientações que objetivem contemplar a maioria da 
população brasileira, visto que o citado documento foi elaborado para todo o território nacional. Dentre as medidas que englobam uma parcela específica da população, existem documentos $^{3}$ elaborados pelos estados, cujo objetivo é adequar as orientações da BNCC para as realidades locais e funcionam como um subsídio extra de orientação docente em um determinado contexto regional. Assim, Rajagopalan (2013b) ressalta a necessidade de uma proposta de política linguística de alcance nacional que possa "mirar a maioria da população e seu bem-estar a curto, médio e longo prazo" (RAJAGOPALAN, 2013b, p.157), sendo necessário responder às seguintes questões: a) por que ensinar determinada língua adicional?; b) por que é do interesse do cidadão brasileiro dominar esse idioma? Desse modo, a atuação política do linguista deve ser em prol do povo como um todo, buscando oferecer melhores condições aos cidadãos comuns no que se refere ao seu posicionamento sobre assuntos relativos à língua. No entanto, entendemos a complexidade que esse processo implica, e, de acordo com Rojo (2013) salientamos a dificuldade de colocar tais diretrizes em prática, visto, por exemplo, os impedimentos institucionais/acadêmicos de um determinado contexto.

Nessa seção, apresentamos as principais vertentes de política linguística e compreendemos o conceito sob uma perspectiva contemporânea mais ampla (cf. SPOLSKY, 2004; SCHIFFMAN, 1996; SHOHAMY, 2006; RAJAGOPALAN, 2013; ROJO, 2013). Todavia, para o presente trabalho, nos concentramos em um dos documentos legais do Estado, cujas diretrizes não necessariamente se refletem nas práticas de planejamento linguístico em si. Salientamos, porém, que, embora nossos objetivos não contemplem aspectos que Shohamy (2006) denomina "política linguística de facto", chamaremos a atenção para situações em que as decisões materializadas no documento oficial analisado apresentam inconsistências entre a legislação e sua prática.

A seguir, apresentamos o marco legislativo e o processo de elaboração, publicação e implementação da BNCC no contexto brasileiro.

\footnotetext{
${ }^{3}$ Por exemplo, Minas Gerais, perante a aprovação das novas Bases Curriculares Nacionais, elabora um novo documento - à luz da BNCC - e publica, em 2018, o Currículo Referência de Minas Gerais (CRMG) (cf. MINAS GERAIS, 2018) documento responsável por delimitar as orientações aos professores do estado mineiro.
} 


\section{A BNCC, A LÍNGUA ADICIONAL E AS COMPETÊNCIAS TECNOLÓGICAS}

Para discutirmos questões relacionadas à língua adicional e às competências tecnológicas na BNCC, primeiramente nos deteremos ao contexto de elaboração, publicação e implementação desse documento. Em seguida, focaremos na análise das competências selecionadas para este estudo.

\section{A legislação em torno da BNCC e algumas considerações sobre língua adicional}

O documento que implementa reformas no Ensino Básico e que reforça a criação da BNCC, é a Lei $13.415^{4}$ (BRASIL, 2017b), sancionada em 16 de fevereiro de 2017 e cujo texto modifica pontos da Lei 9.394 de Diretrizes e Bases da Educação Nacional (BRASIL, 1996). Por meio dessa legislação, reforça-se a criação de um currículo nacional de base e define-se os componentes curriculares essenciais no ensino de línguas adicionais, conforme exposto nos artigos apresentados a seguir (BRASIL, 2017b, grifo nosso):

$\S 5^{\circ}$ do Art. $2^{\circ}$ No currículo do ensino fundamental a partir do sexto ano, será ofertada a língua inglesa.

Art. $3^{\circ}: \quad \S 4^{o}:$ Os currículos do ensino médio incluirão ${ }^{5}$, obrigatoriamente, o estudo da língua inglesa e poderão ofertar outras línguas, em caráter optativo, preferencialmente o espanhol, de acordo com a disponibilidade de oferta, locais e horário definidos pelos sistemas de ensino.

Art. 22. Fica revogada a Lei 11.161, de 5 de agosto de $2005^{6}$

Inicialmente, observamos que no texto da Lei $\mathrm{n}^{\circ} 13.415$ o inglês é colocado como língua de referência no Ensino Básico, não especificando a condição dessa língua como

\footnotetext{
${ }^{4}$ Em 16 de fevereiro de 2017, a Lei 13.415, dentre outras disposições,revoga a lei $\mathrm{n}^{\mathrm{o}} 11.161$, de 5 de agosto de 2005, (Art. $22^{\circ}$ ), que estabelecia a oferta obrigatória de ensino de língua espanhola nos currículos plenos de ensino médio e a partir da $5^{\text {a }}$ série para o ensino fundamental no sistema educacional brasileiro. Mais informações disponíveis em:<http://www.planalto.gov.br/ccivil_03/_Ato2015-2018/2017/Lei/L13415.htm>. Acesso em: 29 set. 2020.

${ }^{5}$ Ainda que nosso foco esteja voltado às duas últimas séries do ensino fundamental, $8^{\circ}$ e $9^{\circ}$ ano, nos parece relevante destacar a importância do ensino médio, uma vez que esta ênfase pode contribuir com reflexões sobre o texto da BNCC no componente curricular língua adicional.

${ }^{6}$ Lei que tornava obrigatória a oferta da língua espanhola no sistema educacional brasileiro e que foi revogada pela Lei 13.415. Disponível em: <http://www.planalto.gov.br/ccivil_03/_Ato20042006/2005/Lei/L11161.htm>. Acesso em: 29 set. 2020.
} 
franca $^{7}$, adicional ou estrangeira. A compreensão do inglês mostra-se livre para as concepções "adicional" ou "estrangeira" de acordo com as afiliações teóricas dos profissionais da educação linguística, o que nos retoma os estudos de Rojo (2013), quando a autora salienta as maneiras de se fazer política linguística, destacando a necessidade de um planejamento e execução de políticas públicas coerentes e monitoradas de modo a direcionar os rumos dessas ações políticas. Apontamos, então, para a necessidade de um esclarecimento acerca da concepção de língua adotada pelo documento que rege o Ensino Básico em nível nacional, ou seja, a BNCC.

Em segundo lugar, essas orientações cancelam a possibilidade da oferta obrigatória da língua espanhola, colocando-a como língua opcional preferente dentre os componentes curriculares da BNCC apenas para o nível do ensino médio. Conforme é possível observar, a ausência de diretrizes na BNCC para a inclusão da língua espanhola pode ser justificada pela condição optativa que esse idioma ocupa na Lei $\mathrm{n}^{\circ} 13.415$. Isso nos leva a compreender, na BNCC, a informação de que as diretrizes ali expressas para a língua inglesa podem ser ajustadas para o ensino de outros idiomas. Essas afirmações podem ser relacionadas com as implicações de políticas linguísticas que Diniz e Ribeiro da Silva (2019) exemplificam quando a promoção de uma determinada língua, neste caso a escolha pelo inglês, coloca os demais idiomas em uma posição hierárquica inferior - o espanhol, na condição atual de língua adicional optativa, teria um status diferente do inglês, cuja oferta é obrigatória.

Ao mesmo tempo, a Lei $\mathrm{n}^{\circ} 13.415$ (BRASIL, 2017b) garante, no parágrafo primeiro do artigo terceiro, que a BNCC pode adaptar-se às realidades social, econômica, ambiental e cultural dos locais atendidos pelos diferentes sistemas de ensino no Brasil, oferecendo-se abertura a ajustes que os sistemas de ensino devem considerar na elaboração de seus currículos locais. Tais ajustes poderiam incluir ações voltadas para a oferta de outras línguas adicionais que estejam vigentes no contexto sociocultural atendidos pela escola. Nesse sentido, Rajagopalan (2013a), destaca a política linguística como meio para conduzir reflexões em torno de línguas específicas que se traduzam em ações concretas de interesse público relativo às línguas, neste caso, adicionais. Essas ações concretas seriam o que Calvet $(2002,2007)$ distingue como planejamento linguístico.

\footnotetext{
${ }^{7}$ Estamos cientes de que, ainda que falte essa definição na lei em questão, o texto da BNCC contempla a condição de aprendizagem do inglês como língua franca.
} 
Contudo, constatamos que na BNCC não há orientações gerais que subsidiem estas práticas, por exemplo, na oferta da língua espanhola, como idioma adicional preferente na oferta opcional.

$\mathrm{Na}$ prática docente, o planejamento para outras línguas adicionais a partir da BNCC implicaria adaptações das orientações da língua inglesa para se adequar ao público, caso o objetivo de ensino-aprendizagem seja trabalhar com outra língua. Uma constatação disso seria a proposta de quantificadores na BNCC, listados no quadro de competências, no eixo conhecimentos linguísticos, campo gramática, em que há orientações em inglês para os aprendizes do $8^{\circ}$ ano. Para o trabalho com a língua espanhola, esse conteúdo teria que ser adaptado para alunos do $6^{\circ}$ ou $7^{\circ}$ ano, a depender do que sugerem também os currículos regionais e institucionais dessas séries na escola.

Por tratar-se de um documento basilar, o texto da BNCC orienta a elaboração de currículos locais, contudo, há questões que no próprio documento não encontram-se claramente definidos na área de linguagens, o que pode comprometer a qualidade da transposição que se faz da teoria para a prática. Por exemplo, na concepção teórica da BNCC há especificações para o desenvolvimento de diferentes habilidades comunicativas a partir de gêneros discursivos. Todavia, quando consultamos o quadro de competências nesse documento oficial, a noção de gênero não se expressa claramente nas habilidades orais do $8^{\circ}$ ano. Outro exemplo que poderíamos apontar encontra-se no eixo dos conhecimentos linguísticos, cujos pilares são o estudo do léxico e da gramática. $\mathrm{Na}$ descrição desse eixo, observamos uma perspectiva de ensino discursiva. Contudo, no quadro de competências desse eixo, nos campos do léxico e da gramática, nos deparamos com listas de expoentes funcionais, sem orientações para aplicação prática dos mesmos em contextos de uso. A depender da formação e da percepção que o professor lançar sobre a BNCC, esse ponto pode não ser refletido no fazer docente, o que, de certa forma, mantém o sistema de ensino desigual tanto em condições de estrutura física ou cultural, quanto na composição curricular que poderia ser mais próxima na abordagem de seus componentes ou nas técnicas para se trabalhar diferentes habilidades comunicativas.

Dadas estas considerações, passamos à discussão sobre as implicações da BNCC no trabalho docente a partir das diretrizes sobre o uso das tecnologias digitais no desenvolvimento de diferentes habilidades comunicativas em língua adicional. 


\section{As competências na BNCC: possibilidades no desenvolvimento das competências tecnológicas}

No texto da BNCC, há previsão de direitos essenciais e objetivos de aprendizagem por meio do trabalho com competências e habilidades a serem desenvolvidas pelos estudantes ao longo da escolaridade (BRASIL, 2017a). Nesse documento, a área de Linguagens é composta, dentre outros, pelo componente curricular Língua Inglesa - Anos Finais e está organizado em eixos, unidades temáticas, objetos de conhecimento e habilidades. Além da diversidade, nos pilares da BNCC (BRASIL, 2017a) devem ser garantidos os direitos de igualdade e equidade, princípios que deveriam orientar os currículos de instâncias regionais, estaduais, municipais etc. Em outras palavras, as políticas linguísticas deveriam propor orientações que objetivem contemplar os interesses da maioria da população brasileira, visto a elaboração do documento para todo o território nacional (RAJAGOPALAN, 2013b).

A noção de competência é central na BNCC (BRASIL, 2017a) e pressupõe outras quatro dimensões, isto é, habilidade, atitude, valores e conhecimento. Além disso, os organizadores curriculares ou competências gerais perpassam os diversos níveis da Educação Básica: 1) conhecimento; 2) pensamento científico, crítico e criativo; 3) repertório cultural; 4) comunicação; 5) cultura digital; 6) trabalho e projeto de vida; 7) argumentação; 8) autoconhecimento e autocuidado; 9) empatia e cooperação; 10) responsabilidade e cidadania. Notamos como a competência geral número 5, "cultura digital", é separada das demais e, no texto de apresentação, está justificada pelo "avanço e [...] multiplicação das tecnologias de informação e comunicação e do crescente acesso a elas pela maior disponibilidade de computadores, telefones celulares, tablets e afins", como se essa asserção fosse a realidade de muitos estudantes brasileiros. Ademais, afirma-se que "os estudantes estão dinamicamente inseridos nessa cultura, não somente como consumidores" (BRASIL, 2017a, p. 61). Em relação a essa afirmação, questionamonos acerca de quais estudantes brasileiros - e como - estão inseridos nessa cultura digital. Notamos, nessa generalização, a potencial dificuldade que Rojo (2013) identifica no planejamento linguístico em um contexto diverso tanto no nível nacional quanto regional.

Nessa direção, no documento da BNCC há um apelo às instituições escolares como agentes para "estimular a reflexão e a análise aprofundada" de forma a desenvolver nos 
estudantes "uma atitude crítica em relação ao conteúdo e à multiplicidade de ofertas midiáticas e digitais" (BRASIL, 2017a, p. 61). Ao mesmo tempo, ressalta-se que a escola deveria educar para "usos mais democráticos das tecnologias e para uma participação mais consciente na cultura digital" (BRASIL, 2017a, p. 61). Em outras palavras, entendemos que muitas vezes a política linguística explicitada em documentos oficiais não necessariamente é condizente com o que ocorre nas práticas sociais (cf. SPOLSKY, 2004; SHOHAMY, 2006; DINIZ; RIBEIRO DA SILVA, 2019).

No tocante às seis competências específicas para línguas adicionais, analisamos e sistematizamos, no quadro a seguir, aspectos relacionados às competências digitais (competências II e V) para os últimos anos do ensino fundamental. 
Quadro 1. Competências digitais na BNCC no componente curricular língua inglesa

\section{COMPETÊNCIAS ESPECIFICAS DE LÍNGUA INGLESA PARA $O$ ENSINO FUNDAMENTAL:}

(II) Comunicar-se na lingua inglesa, por meio do uso variado de linguagens em midias impressas ou digitais, reconhecendo-a como ferramenta de acesso ao conhecimento, de ampliação das perspectivas e de possibilidades para a compreensão dos valores e interesses de outras culturas e para o exercicio do protagonismo social.

(V) Utilizar novas tecnologias, com novas linguagens e modos de interação, para pesquisar, selecionar, compartilhar, posicionar-se e produzir sentidos em práticas de letramento na língua inglesa, de forma ética, critica e responsável.

\begin{tabular}{|c|c|c|}
\hline EIXO & $8^{\circ}$ ANO & $9^{\circ}$ ANO \\
\hline [1] Oralidade & Não especifica competências digitais. & $\begin{array}{l}\text { (EF09LI04) Expor resultados de } \\
\text { pesquisa ou estudo com o apoio de } \\
\text { recursos, tais como notas, gráficos, } \\
\text { tabelas, entre outros, adequando as } \\
\text { estratégias de construção do texto } \\
\text { oral aos objetivos de comunicação e } \\
\text { ao contexto (p. } 261 \text { ). }\end{array}$ \\
\hline [2] Leitura & $\begin{array}{l}\text { (EF08LI07) Explorar ambientes virtu- } \\
\text { ais e/ou aplicativos para acessar e usu- } \\
\text { fruir do patrimônio artístico literário em } \\
\text { língua inglesa (p. } 257 \text { ). }\end{array}$ & $\begin{array}{l}\text { (EF09LI08) Explorar ambientes vir- } \\
\text { tuais de informação e socialização, } \\
\text { analisando a qualidade e a validade } \\
\text { das informações veiculadas (p. } 261 \text { ). }\end{array}$ \\
\hline [3] Escrita. & $\begin{array}{l}\text { (EF08LI11) Produzir textos (co- } \\
\text { mentários em fóruns, relatos pessoais, } \\
\text { mensagens instantâneas, tweets, repor- } \\
\text { tagens, histórias de ficção, blogues, en- } \\
\text { tre outros), com o uso de estrategias de } \\
\text { escrita (planejamento, produção de ras- } \\
\text { cunho, revisão e edição final), apontan- } \\
\text { do sonhos e projetos para o futuro (pes- } \\
\text { soal, da familia, da comunidade ou do } \\
\text { planeta) (p. 257). }\end{array}$ & $\begin{array}{l}\text { (EF09LI12) Produzir textos (in- } \\
\text { fográficos, forruns de discussão on- } \\
\text { line, fotorreportagens, } \\
\text { campanhas publicitárias, memes, en- } \\
\text { tre outros) sobre temas de interesse } \\
\text { coletivo local ou global, que revelem } \\
\text { posicionamento critico (p. 262). }\end{array}$ \\
\hline $\begin{array}{l}\text { [4] Estudo do } \\
\text { léxico }\end{array}$ & Não especifica competências digitais. & $\begin{array}{l}\text { (EF09LI13) Reconhecer, nos novos } \\
\text { gêneros digitais (blogues, mensagens } \\
\text { instantâneas, tweets, } \\
\text { entre outros), novas formas de escri- } \\
\text { ta (abreviação de palavras, palavras } \\
\text { com combinação de } \\
\text { letras e numeros, pictogramas, sim- } \\
\text { bolos gráficos, entre outros) na con- } \\
\text { stituição das mensagens (p. } 262 \text { ). }\end{array}$ \\
\hline
\end{tabular}

Fonte: Compilado elaborado pelas autoras, adaptado de Brasil (2017a), diversas páginas. 
Conforme mostramos no quadro (1), centramo-nos apenas em duas das seis competências específicas para Língua Inglesa, por se relacionarem a aspectos que envolvem competências digitais. Por um lado, na competência específica número (II) há relação, mesmo que de forma superficial, ao desenvolvimento de competências digitais. Por outro, na competência específica número (V), há menção direta ao emprego de novas tecnologias, linguagens e modos de interação. Enquanto na competência específica (II) o objetivo é, por meio da comunicação na língua adicional, a ampliação de perspectivas, valores e interesse por outras culturas, na competência específica (V) busca-se, por meio da produção de sentidos em língua adicional, o desenvolvimento de práticas que possam contribuir com o letramento crítico.

Em relação ao Eixo Oralidade [1], no texto da BNCC não se especificam competências digitais para o $8^{\circ}$ e o $9^{\circ}$ ano e apenas sugere-se "expor resultados [..] com o apoio de recursos [diversos]" (BRASIL, 2017a, p. 261), sem mencionar a apropriação de ferramentas digitais para a produção oral. Ademais, verificamos que no texto de apresentação do componente curricular há menção às práticas da linguagem envolvendo compreensão oral, porém com um detalhamento assimétrico se comparada à produção oral. Assim, o documento limita-se a afirmar que "a oralidade também proporciona o desenvolvimento de uma série de comportamentos e atitudes - como se arriscar e se fazer compreender, dar voz e vez ao outro, entender e acolher a perspectiva do outro, superar mal-entendidos e lidar com a insegurança" (BRASIL, 2017a, p. 243). Além disso, a orientação para o trabalho pedagógico se resume a uma lista de "recursos midiáticos verbo-visuais" (BRASIL, 2017a, p. 243) em que são citados cinema, internet e televisão como exemplos de materiais autênticos, mas sem especificações para o desenvolvimento da produção oral.

Nesse mesmo eixo, destacamos que, a depender da formação do professor que ministra as aulas para o $8^{\circ}$ ano, essa lacuna no trabalho com habilidade oral pode fazer com os alunos percam a oportunidade de vivenciarem práticas de uso de recursos digitais, o que pode limitar o desenvolvimento dessa habilidade, ainda que de forma simples, isenta do nível de argumentação exigido no $9^{\circ}$ ano no mesmo eixo. Ainda que os estudantes tenham oportunidade de acessar às tecnologias digitais, não podemos afirmar que todos tenham autonomia e engajamento de se apropriarem dos recursos digitais em favor da expansão da sala de aula, ou seja, do que estão estudando na escola. 
No Eixo Leitura [2], para o $8^{\circ}$ e $9^{\circ}$ anos, orienta-se um trabalho em ambientes virtuais. Enquanto no $8^{\circ}$ o foco é no conteúdo literário, no $9^{\circ}$ ano a diretriz é mais ampla e considera "ambientes virtuais de informação e socialização" (BRASIL, 2017a, p. 261). Na apresentação desse eixo, explicitam-se algumas implicações da apropriação de gêneros discursivos "principalmente pelos meios digitais [...] posicionando-se de forma crítica" (BRASIL, 2017a, p. 244). Contudo, as estratégias para o exercício da criticidade no eixo de leitura não estão claramente demonstradas e não há orientações conceituais do que seja leitura crítica.

Duboc (2014), baseada em Freebody (2008), define letramento crítico como

desenvolvimento de habilidades que capacitem o aluno a ler criticamente as práticas sociais e institucionais e a perceber a construção social e situada do texto e da linguagem por meio da compreensão de suas fontes, propósitos, interesses e condições de produção (DUBOC, 2014, p. 83).

A partir da definição exposta, sugerimos a reflexão de que a criticidade aplicada ao eixo de leitura pressupõe a estratégia de percepção da construção social, dos propósitos e das condições de produção dos gêneros que circulam pelo ambiente virtual.

Consideramos importante destacar a ausência de diretrizes no trabalho com a leitura em sala de aula sustentado na noção de gêneros discursivos. Esclarecemos que compartilhamos a visão de Bakhtin (1997) que parte das práticas sociais e vão em direção ao trabalho com gêneros discursivos (BAKHTIN, 1997), ou seja, o ponto de partida são situações comunicativas reais em diferentes contextos com enfoque na língua em uso e na ampliação da visão de mundo por meio do contato com outras culturas e experiências de vida, o que contribuiu para o desenvolvimento da criticidade, da autonomia e da politização dos alunos. Assim, de acordo com Koch (2003, p. 57), "o conhecimento não consiste apenas em uma coleção estática de conteúdos de experiência, mas também em habilidades para operar sobre tais conteúdos e utilizá-los na interação social”.

Convém salientarmos que nesse mesmo eixo, no $9^{\circ}$ ano, é orientado que o aluno seja preparado para verificar a validade das informações lidas e, diante disso, apontamos para a ausência de um descritor que busque trabalhar, no aspecto crítico da leitura (cf. COSCARELLI; RIBEIRO, 2005; DUBOC, 2014), as diferentes condições em que um texto pode ser lido em função do suporte digital e perante a influência de diferentes modos semióticos no ambiente digital que podem contribuir com distintas formas de recepção e 
interpretação de uma mesma informação.

Ainda sobre as diretrizes do eixo de leitura, consideramos necessária a explicitação de orientações que esclareçam ao professor o trabalho com diferentes gêneros digitais em distintos níveis de abstração da compreensão escrita, uma vez que o contexto digital requer que o aluno compreenda que acessar livremente a rede é também um exercício de ler diferentes discursos em distintos layouts.

No que diz respeito ao Eixo Escrita [3], para o $8^{\circ}$ e $9^{\circ}$ anos orienta-se a produção de textos, dentre os quais são citados alguns gêneros digitais. Contudo, notamos diferença na descrição desses objetivos, ou seja, enquanto para $08^{\circ}$ ano sugere-se $o$ desenvolvimento de estratégias de escrita, para o $9^{\circ}$ ano espera-se produções "que revelem posicionamento crítico" (BRASIL, 2017a, p. 262). Na apresentação do Eixo Escrita, busca-se uma escrita "que se inicia com textos que utilizam poucos recursos verbais [...] e se desenvolve para textos mais elaborados" (BRASIL, 2017a, p. 244). Essa visão considera o estudante como produtor de textos escritos, porém questionamo-nos acerca da apropriação da escrita, da progressão da criticidade e das implicações em termos de políticas linguísticas levantadas por Rajagopalan (2013b) que orientam, dentre outros, o interesse e os objetivos do(s) cidadão(s) brasileiro(s) em querer dominar certas habilidades da língua adicional que está estudando.

Partindo dos pressupostos de Luke e Freebody (1997) acreditamos que o trabalho com a escrita, tanto para o $8^{\circ}$ quanto para o $9^{\circ}$ ano, considerem a exploração de recursos discursivos na construção de sentido ao longo da produção textual de gêneros digitais ${ }^{8}$. Além disso, sugerimos que esse trabalho leve em consideração a interlocução como expressão das ideologias nessas produções digitais, discutindo a diversidade e a expansão de visões de mundo por meio de um texto.

Nesse sentido, ainda no Eixo Escrita, destacamos a necessidade de produção de gêneros que requeiram posicionamento crítico dos alunos do $8^{\circ}$ ano no exercício da escrita, com a devida progressão até chegar ao $9^{\circ}$ ano, para que seja uma produção mais desafiadora e crítica (cf. FARACO; TEZZA, 2001). Acreditamos que essa orientação, expressa de forma explícita, poderia ser combinada com a produção textual colaborativa e com a produção de diferentes versões de um mesmo texto, essa última, já destacada no

\footnotetext{
${ }^{8}$ No trabalho crítico da escrita, consideramos que as noções éticas de autoria e referenciação sejam trabalhadas pelo professor de maneira progressiva entre o $8^{\circ}$ e o $9^{\circ}$ ano.
} 


\section{REVISTA $\mathbf{X}$}

descritor desse eixo para o $8^{\circ}$ ano.

Finalmente, no Eixo Estudo do léxico [4], não há especificações para o trabalho das competências digitais para o $8^{\circ}$ ano. Já para o $9^{\circ}$ ano há indicações para um trabalho com gêneros digitais ${ }^{9}$ no que diz respeito às formas de escrita; porém, carece de orientações para apropriação dessas competências.

Acreditamos que, por tratar-se de um documento basilar que visa estabelecer diretrizes para Educação Básica e oferecer subsídios para que os profissionais da educação as executem, seria fundamental que a BNCC fornecesse esclarecimentos sobre o conceito de letramento digital. ${ }^{10}$ Consideramos importante observar que o termo "produção de texto", nesta definição, não delimita a modalidade em que o texto será composto, e salientamos a importância de se considerar a aplicação desse conceito nas diferentes competências e habilidades expostas na BNCC. Ainda sobre o letramento digital, seria interessante que o documento considerasse as realidades com as quais os professores e os sistemas de Ensino Básico podem se deparar, ou seja, com os níveis de letramento digital $^{11}$, e possibilitar a organização de documentos oficiais em diferentes esferas (regional, estadual, municipal, escolar, disciplinar). Nessas instâncias, deveria concretizarse a contextualização das diretrizes nacionais de acordo com as especificidades da(s) comunidade(s) envolvida(s).

\section{CONSIDERAÇÕES FINAIS}

Ao longo deste estudo, buscamos compreender como as orientações presentes na BNCC referem-se ao ensino de línguas adicionais e ao desenvolvimento de competências tecnológicas e seus impactos para o fazer docente em sala de aula. Para encerrarmos este

\footnotetext{
${ }^{9}$ Dentre os gêneros digitais, na BNCC são mencionadas alternativas para explorar o eixo estudo do léxico para revisão de vocabulário em plataformas de jogos e de nuvem de palavras para $8^{\circ}$ ano e a utilização de plataformas para interação em vídeo para prática oral no caso do $9^{\circ}$ ano.

${ }^{10}$ Como sugestão, destacamos as definições de Coscarelli e Ribeiro (cf. 2005) como práticas sociais de leitura e de produção de textos com apoio das tecnologias digitais, além do Glossário CEALE, disponível em: $\quad<$ http://www.ceale.fae.ufmg.br/app/webroot/glossarioceale/referencia/coscarelli-c-v-ribeiro-a-e-orgsletramento-digital-aspectos-sociais-e-possibilidades-pedag-gicas-belo-horizonte-aut-ntica-2005->. Acesso em: 29 set. de 2020.

${ }^{11}$ Martin e Vestifrid (2016) ampliam a discussão de Prensky (2001), quando destacam que nem todas as habilidades tecnológicas se valem plenamente para as gerações mais jovens e propõem reflexões sobre os níveis de apropriação digital para usuários mais jovens.
} 
artigo, retomamos as duas perguntas que o direcionam.

Com relação à primeira pergunta, como a BNCC orienta o trabalho com as diferentes habilidades comunicativas em língua adicional e de que forma essas orientações impactam o fazer do professor?, nossa pesquisa concluiu que são elaboradas diretrizes apenas com foco na língua inglesa e sugere-se que o professor de uma língua adicional diferente do inglês faça a transposição daquelas estabelecidas para a língua inglesa. Ressaltamos que o ensino de inglês não dispõe dos mesmos componentes funcionais de línguas adicionais de outras origens, como a língua espanhola, por exemplo, o que poderia implicar em diferenças de níveis de ensino para uma mesma série educativa $\left(6^{\circ}, 7^{\circ}, 8^{\circ}\right.$ e $9^{\circ}$ ano) e, consequentemente, localizamos lacunas na orientação aos professores de línguas adicionais diferentes do inglês. Sobre as orientações teóricas que envolvem o ensino de língua adicional, destacamos a importância do texto da BNCC tecer esclarecimentos acerca dos conceitos de interculturalidade, multimodalidade, leitura crítica e letramento digital por ser um documento basilar que direciona o Ensino Básico em todo o Brasil, a fim de contribuir com a formação de profissionais da educação que dele se apropriam para validarem tais diretrizes. Acreditamos que, por tratar-se de um documento que estabelece direcionamentos para Educação Básica e oferece subsídios para que os profissionais da educação as executem, é fundamental que forneça esclarecimentos sobre esses conceitos que fazem parte das orientações presentes no documento.

Quanto à segunda pergunta deste estudo, como a BNCC orienta o uso das tecnologias digitais para o desenvolvimento das diferentes habilidades comunicativas em línguas adicionais?, concluímos que o texto da BNCC traz orientações relevantes, pertinentes e organizadas sobre o trabalho com as diferentes habilidades comunicativas para as séries finais do ensino fundamental II ( $8^{\circ}$ e $9^{\circ}$ ano). Contudo, nossa investigação apontou que as normativas ali expressas podem ser ampliadas e contempladas com o preenchimento de lacunas entre as duas séries focalizadas. Sobre o eixo oralidade, é importante destacar a necessidade de orientações que distingam o trabalho voltado diretamente à produção oral e o trabalho voltado em prol da oralidade que envolve a habilidade de compreensão oral para o $8^{\circ}$ e o $9^{\circ}$ ano. No eixo lexical, por sua vez, nossa análise salientou a necessidade de se esclarecer, de forma progressiva, normativas que orientem o trabalho criativo e contextualizado a esse componente linguístico com apropriação de recursos das tecnologias digitais. Finalmente, em relação aos eixos leitura 
e escrita, observamos a necessidade de maior exploração do componente crítico associado à apropriação das tecnologias em sala de aula.

Como instrumento de política linguística, consideramos que a BNCC como um documento oficial que, pela determinação do foco estar centrado no ensino-aprendizagem da língua inglesa, contribui com a acentuação da tensão entre o espaço que as línguas adicionais ocupam no sistema educacional brasileiro. A partir da escolha políticoeducacional evidenciada no texto, em que é conferido diferente status às línguas adicionais, outras línguas adicionais como o espanhol ocupam um lugar de hierarquia inferior, na condição de optativas. Esse tipo de diretriz terá consequências, dentre outros, na percepção que professores, alunos, pais e outros atores da sociedade civil e agentes de políticas linguísticas têm em relação a determinadas línguas adicionais, que, junto com a legislação vigente, coloca ao espanhol, uma das línguas majoritárias do continente, em segundo plano em relação a uma língua de status global, como o inglês. Além disso, constatamos a necessidade de maior transposição da teoria preconizada nesse documento à prática docente, uma vez que a BNCC é sustentada por um embasamento teórico relevante no campo da línguas adicionais, contudo, os conceitos não se veem claramente sugeridos no quadro de competências do documento. Isso se mostra importante devido, sobretudo, à relevância nacional da BNCC, como instrumento de política linguística que orienta o que deve ser trabalhado nas escolas de todo o Brasil, o que justifica a necessidade de esclarecimentos, uma vez que há professores com diferentes formações e podem interpretar as orientações de formas distintas ou podem ter dificuldades em colocar em prática o que é orientado no documento.

Encerramos esta pesquisa chamando a atenção para os debates educacionais contemporâneos (cf. MONTE MOR, 2013), que salientam a necessidade de desenvolver as várias habilidades dos estudantes, inclusive o letramento crítico, para a vivência numa sociedade que enfrenta fenômenos como a globalização e a ampla presença da tecnologia digital.

\section{REFERÊNCIAS}

BAKHTIN, M. Estética da criação verbal. Os gêneros do discurso. $2^{\mathrm{a}}$ ed. São Paulo: Martins Fontes, 1997. 
BRASIL. Congresso Nacional. Lei Federal 13.005, de 25 de junho de 2014. Aprova o Plano Nacional de Educação - PNE e dá outras providências. Brasília: MEC/SEF, 2014.

. Congresso Nacional. Lei $n^{o} 9.394$ de 20 de dezembro de 1996. Estabelece as diretrizes e bases da educação nacional. Diário Oficial da União, Poder. Brasília, 1996.

. Ministério da Educação. Base Nacional Comum Curricular: Educação Infantil e Ensino Fundamental. Brasília: MEC/SEF, 2017a.

Congresso Nacional. Lei $n^{\circ}$ 13.415, de 16 de fevereiro de 2017. Altera as Leis 9.394, de 20 de dezembro de 1996, que estabelece as diretrizes e bases da educação nacional, e 11.494, de 20 de junho 2007, que regulamenta o Fundo de Manutenção e Desenvolvimento da Educação Básica e de Valorização dos Profissionais da Educação, a Consolidação das Leis do Trabalho CLT, aprovada pelo Decreto-Lei no 5.452, de 1o de maio de 1943, e o Decreto-Lei no 236, de 28 de fevereiro de 1967; revoga a Lei no 11.161, de 5 de agosto de 2005; e institui a Política de Fomento à Implementação de Escolas de Ensino Médio em Tempo Integral. Portal da Legislação, Brasília, 2017b. Disponível em: $\quad<$ http://www.planalto.gov.br/ccivil_03/_Ato20152018/2017/Lei/L13415.htm>. Acesso em: 29 set. 2020.

- Ministério da Educação. Parâmetros Curriculares Nacionais (PCNs). Ensino Fundamental. Brasília: MEC/SEF, 1997.

Ministério da Educação. Parâmetros Curriculares Nacionais (PCNs). Língua Estrangeira. Terceiro e quarto ciclos do Ensino Fundamental. Brasília: MEC/SEF, 1998.

. Ministério da Educação. Diretrizes Curriculares Nacionais da Educação Básica. Brasília: MEC/SEF, 2013.

CALVET, L. J. As políticas linguísticas. Tradução de Isabel de Oliveira Duarte; Jonas Tenfen; Marcos Bagno. São Paulo: Parábola Editorial: IPOL, 2007.

. Sociolinguística: uma introdução crítica. São Paulo: Parábola, 2002.

COSCARELLI, C. V.; RIBEIRO, A. E. (Orgs.). Letramento digital: aspectos sociais e possibilidades pedagógicas. Belo Horizonte: Ceale; Autêntica, 2005.

DINIZ, L. R. A; SILVA, E. R. Remarks on the Diversity of Theoretical Perspectives in Language Policy Research. Revista Brasileira de Linguística Aplicada, Belo Horizonte, v.19, n.2, p.249-263, jun., 2019. Disponível em: $<$ http://www.scielo.br/scielo.php?script=sci_arttext\&pid=S198463982019000200249\&lng=en\&nrm=iso $>$. Acesso em: 29 set. 2020.

DUBOC, A. P. Letramento crítico nas brechas da sala de línguas estrangeiras. In: TAKAKI, N. H.; MACIEL, R. F. (Orgs). Letramentos em terra de Paulo Freire. Campinas: Pontes, p.209-229, 2014. 
FARACO, C. A.; TEZZA, C. Prática de texto para estudantes universitários. São Paulo: Ed. Vozes, 2001.

JORDÃO. C. M. ILA - ILF - ILE - ILG: Quem dá conta?. Revista Brasileira de Linguística Aplicada, Belo Horizonte, v. 14, n. 1, p. 13-40, 2014. Disponível em: $<$ http://www.scielo.br/scielo.php?pid=S1984-63982014000100002\&script=sci_arttext $>$.

Acesso em: 29 set. 2020.

FREEBODY, P. Critical literacy education: On living with "innocent language." In: STREET, B.; HORNBERGER, N. H. (Orgs.). Encyclopedia of language education. 2nd ed. Secaucus: Springer, v. 2, p. 107-118, 2008.

LEROY, H. R. Dos sertões para as fronteiras e das fronteiras para os sertões: as (in)visibilidades das identidades performativas nas práticas translíngues, transculturais e decoloniais no ensino aprendizagem de Língua Portuguesa Adicional da UNILA. Tese de Doutorado em Letras. Programa de Pós-Graduação Strictu Sensu em Letras, UNIOESTE, Cascavel, 2018.

LUKE, A.; FREEBODY, P. The social practices of reading. In: MUSPRATT, S.; LUKE, A.; FREEBODY, P. Constructing critical literacies. St Leonards, Australia: Allen \& Unwin, 1997.

MARTIN, M. V; VESTIFRID, P. Tensiones en torno al concepto de "nativos digitales" en el caso de estudiantes universitarios. In: $1^{\circ}$ Jornada sobre las Prácticas Docentes en la Universidad Pública: transformaciones actuales y desafíos para los procesos de formación. La Plata, resúmenes. La Plata: UNLP, p.1347-1356, 2016.

MINAS GERAIS. Secretaria de Estado de Educação. Currículo Referência de Minas Gerais. Língua Inglesa. Brasília: MEC/SEF, 2018.

MOITA LOPES, L. P da. Pesquisa Interpretativista em Linguística Aplicada: a linguagem como condição e solução. D.E.L.T.A.., V.10, n.2, p.329-338, 1994.

MONTE MÓR, W. Crítica e letramentos críticos: reflexões preliminares. In: ROCHA, C. H; MACIEL, R. F. Língua estrangeira e formação cidadã: por entre discursos e práticas. Campinas, SP: Pontes Editores, p.31-50, 2013.

PRENSKY, M. "Nativos e imigrantes tecnológicos". Madrid: editorial SEK, 2001. Disponível em: <http://www.marcprensky.com/writing/PrenskyNATIVOS\%20E\%20INMIGRANTES\%20DIGITALES\%20(SEK).pdf>. Acesso em: 29 set. 2020.

RAJAGOPALAN, K. Política linguística: do que é que se trata, afinal? In: NICOLAIDES, C. et al (Org.). Política e Políticas Linguísticas. Campinas: Pontes Editores, p.19-42, 2013a. 
A política de ensino de línguas no Brasil: história e reflexões prospectivas In: MOITA LOPES, L. P. de (Org.). Linguística Aplicada na Modernidade Recente. São Paulo: Parábola Editorial, p.143-163, 2013b.

ROJO, R. Caminhos para a LA: política linguística, política e globalização. In: NICOLAIDES, Christine; et al. (Org.) Política e políticas linguísticas. Campinas: Pontes Editores, p.63-78, 2013.

SÁ-SILVA, J. R.; ALMEIDA, C. D.; GUINDANI, J. F. Pesquisa documental: Pistas teóricas e metodológicas. Revista Brasileira de História e Ciências Sociais. Ano I, número I, s.p., 2009.

SCHLATTER, M; GARCEZ, P. M. Línguas adicionais (espanhol e inglês). In: Rio Grande do Sul, Secretaria de Estado da Educação, Departamento Pedagógico (Org.). Referenciais curriculares do Estado do Rio Grande do Sul: linguagem, códigos e suas tecnologias. Porto Alegre: Secretaria de Estado da Educação, Departamento Pedagógico, v.1, p.125-172, 2009. Disponível em:

<http://www.educacao.rs.gov.br/dados/refer_curric_vol1.pdf $>$. Acesso em: 29 set. 2020.

SCHIFFMAN, H. F. Linguistic Culture and Language Policy. London; New York: Routledge, 1996.

SHOHAMY, E. G. Language policy: hidden agendas and new approaches. London; New York: Routledge, 2006.

SPOLSKY, B. Language Policy. Cambridge, UK: Cambridge University Press, 2004.

Recebido em: 01 mai. 2020.

Aceito em: 05 out. 2020. 